\title{
Revisitando as extranets de projeto: uma análise dos processos de projeto
}

\author{
Revisiting design extranets: an analysis of design \\ processes
}

\section{Paulo Roberto Pereira Andery Eduardo Marques Arantes}

\section{Resumo}

A s extranets de projeto foram amplamente investigadas há alguns anos. No entanto, pouco esforço tem sido dedicado à análise de como seu uso evoluiu nas empresas de AEC. Nesse sentido, o presente trabalho revisita as extranets de projeto com uma nova perspectiva, analisando evoluções em seu uso. A extranet objeto de estudo foi desenvolvida em parceria entre universidade e empresas, e seu uso foi analisado em dezenas de empreendimentos ao longo de oito anos. O método de pesquisa apresenta a forma de estudo de casos múltiplos. As funcionalidades da extranet foram desenvolvidas de maneira progressiva, e seu uso foi analisado por meio de observação direta de rotinas de trabalho, acesso a todos os documentos de dezenas de empreendimentos, análise do fluxo de trabalho nos empreendimentos e entrevistas com coordenadores de projeto. Entre os principais resultados destacam-se: a) o uso prolongado da ferramenta permitiu que as empresas consolidassem rotinas de gestão do processo de projeto, melhorando a gestão de documentos e as formas de comunicação; b) esse uso não implicou, na maioria dos casos, a criação de novos mecanismos de colaboração entre os usuários, com exceções pontuais; c) o amadurecimento no uso das extranets permitiu a ampliação de seu uso, estendendo-se a outros setores das empresas e fases dos empreendimentos. $\mathrm{O}$ trabalho discute como as extranets, com o uso consolidado nas empresas, podem servir como efetivos instrumentos de colaboração na etapa de projeto.

Palavras-chaves: Extranets de projeto. Colaboração em AEC. Gestão do processo de projeto.
Abstract
Design extranets have been widely studied. However, not much effort has been devoted to analysing how their use has evolved in AEC companies. This paper examines extranets from a new perspective. This study focuses on an extranet developed in partnerships between universities and building companies, and its use was analysed in dozens of projects, over an eight-year period. The research method involved multiple case studies. The features of the extranet were developed progressively, and its use was analysed by means of direct observation of work routines, access to the documents of dozens of projects, design workflow analysis and interviews with project coordinators. The main results highlight that: a) the prolonged use of the tool allowed companies to consolidate the management routines of the design process, improving
document management and communication mechanisms; $b$ ) this usage did not involve, in most cases, the creation of new mechanisms of collaboration between stakeholders, with very few exceptions; c) the maturity in the use of extranets allowed the expansion of their use, extending to other sectors of business and phases of the projects. The paper points out how extranets, through their consolidated use in companies can be effective collaboration tools in the design stage.
Keywords: Design extranets. Collaboration at AEC. Design management.

Paulo Roberto Pereira Andery Universidade Federal de Minas Gerais Belo Horizonte - MG - Brasil

Eduardo Marques Arantes Universidade Federal de Minas Gerais Belo Horizonte - MG - Brasil

Recebido em 09/02/15 Aceito em 17/05/15 


\section{Introdução}

Nos últimos anos tem crescido a preocupação por incrementar as formas de colaboração na execução de projetos em arquitetura, engenharia e construção, e tanto no âmbito empresarial como nos meios acadêmicos se estudam melhores formas de interação entre os agentes envolvidos. Nesse sentido, os conceitos de engenharia simultânea têm evoluído e voltam-se para a constituição de um processo de projeto no qual os agentes assumem papéis e responsabilidades para compartilhar riscos e benefícios, como é o caso do Integrated Project Delivery (AMERICAN..., 2015; DE BLOIS; HERAZO-CUETO, 2011). Na mesma direção, nova forma de concepção, desenvolvimento e construção de empreendimentos tem encontrado nos conceitos de Building Information Modelling (BIM) instrumentos adequados para o desenvolvimento integrado de todas as suas fases.

Se esses conceitos implicam mudanças estruturais nas formas de trabalho que vão além da implementação de tecnologias de informação e comunicação, por outro lado as extranets de projeto continuam as ser amplamente empregadas por empresas como ferramentas de gestão de documentos, comunicação e, em menor escala, efetiva colaboração.

Se na primeira metade da década passada houve diversas pesquisas analisando a implementação das extranets, os resultados alcançados com essa implementação pouco se analisaram nos últimos anos, ainda que tenha se estendido e evoluído o uso dessas ferramentas de gestão da informação e colaboração. Nos últimos anos, houve poucos estudos sobre a utilização dos ambientes colaborativos via web, ou extranets de projeto, e os pesquisadores concentram sua atenção em outras ferramentas.

Como as extranets mantêm-se bastante atuantes no mercado, e por se tratar de tecnologia colaborativa que também se moderniza, seja pelas novas possiblidades de modelagem da informação, seja pela própria existência e evolução natural da tecnologia, o presente artigo revisita os ambientes colaborativos de uma extranet específica para verificar se houve mudanças em relação ao passado, tanto em termos de funcionalidades como na colaboração propriamente dita.

Passados cerca de dez anos, além do fato de analisar possíveis mudanças no uso dos ambientes colaborativos, o trabalho contribui para as discussões em torno da evolução do uso das extranets na medida em que apresentam dois aspectos ainda pouco caracterizados na literatura recente.
O primeiro é o fato de que o ambiente colaborativo estudado foi desenvolvido no âmbito universitário por um grupo de pesquisa em colaboração permanente com as empresas que o utilizaram, de forma que parte das funcionalidades foram desenvolvidas a partir das demandas e necessidades das empresas. Em outras palavras, o desenvolvimento das funcionalidades do sistema do ponto de vista do uso por parte das empresas e empreendimentos pôde ser minuciosamente analisado por um longo período.

Em segundo lugar, o fato de o desenvolvedor do sistema acompanhar a implementação e utilização do ambiente colaborativo em pelo menos cinco empresas e dezenas de empreendimentos permitiu que a análise tivesse um maior número de casos representativos do uso das extranets, ao contrário de grande parte dos trabalhos da literatura, nos quais as fontes de evidências não puderam contar com os bancos de dados dos desenvolvedores dos ambientes colaborativos, e a análise de dados concentrou-se nos usuários das ferramentas, com algumas exceções.

Apresentam-se na sequência alguns conceitos que contextualizam o trabalho. A seguir é brevemente indicado o método de pesquisa e são apresentados e analisados os resultados encontrados.

\section{Extranets de projeto: revisitando a literatura}

Nitithamyong e Skibniewski (2011) definem ambientes colaborativos como sistemas de gerenciamento de projetos estruturados na web, que podem ter funções variadas, desde repositório de informações à utilização de ferramentas de gerenciamento, facilitadoras de efetiva colaboração.

Na mesma linha de raciocínio, Ruikar, Anumba e Carillo (2005) ressaltam que as extranets têm a função de monitorar, controlar, manipular e guardar as informações dos projetos, tanto no sentido de empreendimento como no sentido de concepção de um produto (design), tornando essa informação disponível para os participantes de uma organização temporária (como é o caso das equipes de projeto) ou para uma cadeia de suprimentos.

Diversos autores - veja-se, por exemplo, Liu e Kagioglou (2008) - fizeram estudos comparativos indicando as funcionalidades das extranets orientadas à gestão de projetos, quer seja no sentido de empreendimento, quer seja no sentido de desenvolvimento do produto. Os autores 
sugerem que a comparação entre distintos ambientes pode ser complexa, porque as funcionalidades podem variar significativamente de fabricante para fabricante, e seu desenvolvimento é dinâmico: novas versões com novas funções aparecem com relativa frequência.

Os mesmos autores identificaram como principais funcionalidades das extranets:

(a) módulos administrativos, que permitem a configuração da estrutura do sistema, definem os tipos de acesso e parâmetros de segurança, permitem configurar o uso para múltiplos agentes e projetos, etc.;

(b) funções de gerenciamento de documentos, envolvendo a carga e descarga de documentos, a emissão de notificações, a rastreabilidade dos documentos;

(c) funções de gerenciamento do fluxo de informações e tarefas (workflow and tasks management), integrando tarefas e disciplinas, aplicando ferramentas de gerenciamento de projetos (custo, prazo, escopo) e permitindo a integração de fluxos de trabalho, etc.; e

(d) ferramentas de comunicação.

Essas funcionalidades foram detalhadamente descritas em Wilkinson (2005).

Nitithamyong e Skibniewski (2011) conduziram um dos estudos mais completos e recentes sobre a utilização de extranets em projetos de arquitetura, engenharia e construção. Os autores destacam alguns aspectos como essenciais para o sucesso da implementação. Citam em primeiro lugar o comprometimento e apoio técnico e gerencial da alta administração no âmbito das empresas envolvidas. Também consideram como aspecto crítico a presença de um líder de projeto comprometido com a utilização do ambiente colaborativo, que tenha a possibilidade de dar assistência aos membros da equipe no que diz respeito ao uso da extranet. Chamam também a atenção para o fato de que o sucesso da implementação depende da seleção de uma extranet amigável e fácil de ser utilizada, bem como do treinamento adequado do pessoal envolvido.

Na mesma linha de raciocínio, Wilkinson (2005) sugere condições para que se transcenda da utilização das extranets como meros repositórios para uma situação de efetiva comunicação e colaboração:

(a) estabelecer processos de fluxo de informações claros e bem definidos;

(b) definir claramente dependências entre atividades e disciplinas; $\mathrm{e}$ (c) ter uma clara definição do programa do empreendimento e do escopo de atividades da equipe de projeto.

Esse último aspecto parece ser particularmente importante para que o ambiente colaborativo seja efetivamente uma ferramenta que permita otimizar o fluxo de trabalho, e não só o acesso às informações.

Na mesma direção, Scheer et al. (2007) ressaltam que a gestão do processo de projeto baseada na utilização de instrumentos computacionais de comunicação e gestão, como é o caso das extranets de projeto, requer pelo menos duas condições importantes. A primeira é a criação de um modelo de referência para o processo de projeto. A segunda é a existência de um plano de comunicação entre os agentes envolvidos, o que é também ressaltado por Meloni (2008).

No que diz respeito aos benefícios da utilização das extranets, a literatura, sobretudo entre os anos de 2005 e 2010, debruçou-se sobre o assunto. Uma análise mais ampla, por questões de brevidade, foge do escopo deste trabalho. Entre as pesquisas nessa direção, Ruikar, Anumba e Carillo (2005) ressaltam alguns benefícios da utilização das extranets: a melhoria da comunicação entre os agentes envolvidos; a redução do tempo de resposta, em função da facilidade de acesso à informação; e a possibilidade de rastrear e classificar facilmente as informações. Ainda, a maior transparência na troca de informações pode conduzir a um clima de maior confiança e colaboração. O registro da troca de informações pode ser um importante instrumento de gestão do conhecimento a posteriori, facilitando a identificação e registro das lições aprendidas.

Desde que se crie um roteiro para análise das informações, as extranets podem ser um instrumento útil para identificar durante o processo de projeto dos empreendimentos os gargalos, retrabalhos e fluxos ineficientes de informação e/ou determinação de atividades não agregadoras de valor, dentro da ótica do pensamento enxuto (TRIBELSKY; SACKS, 2010).

Nesse contexto, como indicado acima, o presente trabalho revisita o tema da utilização das extranets de projeto, tendo como diferencial um objeto de pesquisa caracterizado pelo uso prolongado da ferramenta por parte de empresas e empreendimentos, e uma ampla amostragem de empreendimentos objeto de estudo.

Na sequência, o método de pesquisa e os principais resultados são delineados. 


\section{Método de pesquisa}

A presente etapa de trabalho, que envolve o estudo exploratório sobre o uso prolongado das extranets, pode ser considerada, do ponto de vista metodológico, um estudo de caso múltiplo (YIN, 2005).

A análise de dados foi feita com base na implementação e utilização da extranet Sisac, brevemente descrita na sequência, em 95 empreendimentos de construção, caracterizados na Tabela 1, de 5 empresas construtoras e incorporadoras.

A seleção das empresas obedeceu aos critérios de:

(a) implementação e utilização do ambiente colaborativo por um período superior a 8 anos;

(b) existência de um sistema estruturado de workflow no desenvolvimento dos projetos (design management) dos empreendimentos; (c) utilização exclusiva da extranet nos empreendimentos;

(d) utilização em empreendimentos de tipologias diferenciadas, como indicado na Tabela 1; e

(e) disponibilização de dados dos empreendimentos, com autorização de acesso a documentos, fluxos de informação, projetos, registros de comunicação nas mais variadas formas, etc.

Algumas características das empresas estudadas são apresentadas na Tabela 1 .

Observa-se que todas as empresas têm uma posição consolidada no mercado e na sua maioria com um portfolio diversificado de empreendimentos, destacando-se a incorporação e construção de edifícios residenciais e shoppings nas regiões Sudeste e Nordeste do país e modalidades de promoção.

Tabela 1 - Caracterização das empresas e dos empreendimentos analisados

\begin{tabular}{|c|c|c|c|c|c|}
\hline Empresa & $\begin{array}{l}\text { Tempo } \\
\text { de } \\
\text { mercado } \\
\text { (anos) }\end{array}$ & $\begin{array}{l}\text { Segmentos de } \\
\text { atuação }\end{array}$ & $\begin{array}{c}\text { Número e } \\
\text { características dos } \\
\text { empreendimentos } \\
\text { estudados }\end{array}$ & $\begin{array}{c}\text { Âmbito de } \\
\text { aplicação da } \\
\text { extranet }\end{array}$ & Observações \\
\hline A & 50 & $\begin{array}{c}\text { Obras de } \\
\text { infraestrutura } \\
\text { Obras } \\
\text { industriais } \\
\text { Incorporação e } \\
\text { construção de } \\
\text { edifícios }\end{array}$ & $\begin{array}{l}\text { 35: edifícios } \\
\text { residenciais (32) e } \\
\text { comerciais (3) de } \\
\text { alto padrão }\end{array}$ & $\begin{array}{c}\text { Coordenação e } \\
\text { desenvolvimento } \\
\text { de projetos e obra } \\
\text { SGQ da empresa }\end{array}$ & $\begin{array}{l}\text { Atuações nos } \\
\text { setores } \\
\text { rodoferroviário, } \\
\text { saneamento e } \\
\text { urbanização }\end{array}$ \\
\hline B & 40 & $\begin{array}{c}\text { Shoppings } \\
\text { Incorporação e } \\
\text { construção de } \\
\text { edifícios }\end{array}$ & $\begin{array}{l}\text { 30: shoppings (7) e } \\
\text { edifícios } \\
\text { residenciais de alto } \\
\text { padrão (23) }\end{array}$ & $\begin{array}{c}\text { Coordenação e } \\
\text { desenvolvimento } \\
\text { de projetos e obra } \\
\text { SGQ da empresa }\end{array}$ & $\begin{array}{c}\text { Atuação nas } \\
\text { regiões Sudeste e } \\
\text { Nordeste do } \\
\text { Brasil }\end{array}$ \\
\hline $\mathrm{C}$ & 26 & Shoppings & 8 & $\begin{array}{c}\text { Coordenação e } \\
\text { desenvolvimento } \\
\text { de projetos e áreas } \\
\text { correlatas da } \\
\text { empresa }\end{array}$ & $\begin{array}{l}\text { Desenvolvimento, } \\
\text { gerenciamento, } \\
\text { comercialização e } \\
\text { administração de } \\
\text { shoppings }\end{array}$ \\
\hline $\mathrm{D}$ & 17 & $\begin{array}{l}\text { Incorporação e } \\
\text { construção de } \\
\text { edifícios } \\
\text { comerciais e } \\
\text { residenciais }\end{array}$ & $\begin{array}{l}\text { 8: edifícios } \\
\text { comerciais }(2) \text { e } \\
\text { residenciais (6) }\end{array}$ & $\begin{array}{c}\text { Coordenação e } \\
\text { desenvolvimento } \\
\text { de projetos SGQ } \\
\text { da empresa }\end{array}$ & $\begin{array}{c}\text { Especializada em } \\
\text { edifícios } \\
\text { residenciais } \\
\text { litorâneos }\end{array}$ \\
\hline $\mathrm{E}$ & 45 & $\begin{array}{c}\text { Obras } \\
\text { industriais } \\
\text { Obras de } \\
\text { infraestrutura } \\
\text { Incorporação e } \\
\text { construção de } \\
\text { edifícios } \\
\text { residenciais }\end{array}$ & $\begin{array}{l}\text { 15: edifícios } \\
\text { residenciais }(10) \text { e } \\
\text { hotéis }(5) \text { de alto } \\
\text { padrão }\end{array}$ & $\begin{array}{l}\text { Coordenação e } \\
\text { desenvolvimento } \\
\text { de projetos } \\
\text { residenciais e } \\
\text { comerciais }\end{array}$ & $\begin{array}{c}\text { Todos os } \\
\text { empreendimentos } \\
\text { analisados numa } \\
\text { mesma capital do } \\
\text { Brasil }\end{array}$ \\
\hline
\end{tabular}


Em todos os casos os coordenadores do desenvolvimento de projetos foram os responsáveis internos das empresas pela implementação e utilização do sistema colaborativo. Com exceção das empresas B e E, o uso preponderante deu-se por parte do coordenador de projetos e projetistas e outros agentes diretamente envolvidos com a concepção das edificações.

A extranet utilizada nas empresas denomina-se Sistema de Ambientes Colaborativos (Sisac) e foi desenvolvida por grupo de pesquisa em colaboração com as empresas em um projeto que tem 9 anos de duração. As funcionalidades do sistema, além das básicas e comumente utilizadas, foram desenvolvidas inicialmente dentro da universidade, mas com o uso sistêmico do sistema pelas empresas a maioria dos desenvolvimentos surgiu a partir das demandas e necessidades das empresas, sobretudo no que se refere aos serviços associados, tais como relatórios periódicos, sistema de busca às informações, sistema de emails integrado e geração de mapas de notificações e permissões de acesso.

O Sisac é um sistema web específico orientado inicialmente para atender à gestão do processo de projeto que reune diversos recursos em uma mesma interface, numa arquitetura de rede clienteservidor. Foi desenvolvido em linguagem PHP e banco de dados MySQL sobre um servidor Apache (LINUX). O sistema utiliza os recursos tecnológicos que permitem uma completa interação durante as fases de progressão do projeto. Possibilita aos participantes a inserção, visualização e revisão de documentos associados ao projeto, de acordo com permissões e restrições de acesso a funções, definidas pelo coordenador. A Figura 1 mostra o ambiente Sisac com a indicação das principais funcionalidades ou módulos (localizados no cabeçalho do sistema): Administrador, Página Inicial, Agenda, Participantes do Projeto, Gerenciador de Arquivos, Gerenciador de Comunicações, Favoritos e Chat. O conteúdo da página web mostrada na Figura 1 refere-se ao módulo mais utilizado pelos usuários, o Gerenciador de Arquivos, com a indicação de desenhos aprovados do projeto legal de arquitetura de um empreendimento da empresa A. Outras funções e telas do ambiente são descritas ao longo do trabalho.

O Gerenciador de Arquivos permite aos participantes serem notificados automaticamente em virtude das alterações que são realizadas no ambiente. $O$ sistema permite individualizar a leitura e escrita dos avisos conforme o grau de envolvimento dos integrantes no projeto, com a vantagem de centralizar todos os e-mails dos empreendimentos no sistema. A ferramenta suporta também argumentação síncrona, que se realiza por meio de fóruns (com registro para posterior conhecimento) e compartilhamento de informações textuais e visuais.

A integração da informação é realizada por módulos específicos para armazenamento da informação, cujas funções e recursos permitem a interação e a comunicação entre os atores envolvidos. Nessa direção, as ferramentas mais utilizadas pelas empresas são o Gerenciador de Arquivos e o Gerenciador de Comunicações, que oferecem uma coleção de mecanismos de cooperação e comunicação para uso no processo de projeto, permitindo a estruturação de problemas de projeto e a consistência dos processos de tomada de decisão, além do registro temporal de suas argumentações. Detalhes sobre o funcionamento da extranet são indicados em Arantes (2008).

Figura 1 - Ambiente colaborativo - Principais funções e tela do Gerenciador de Arquivos

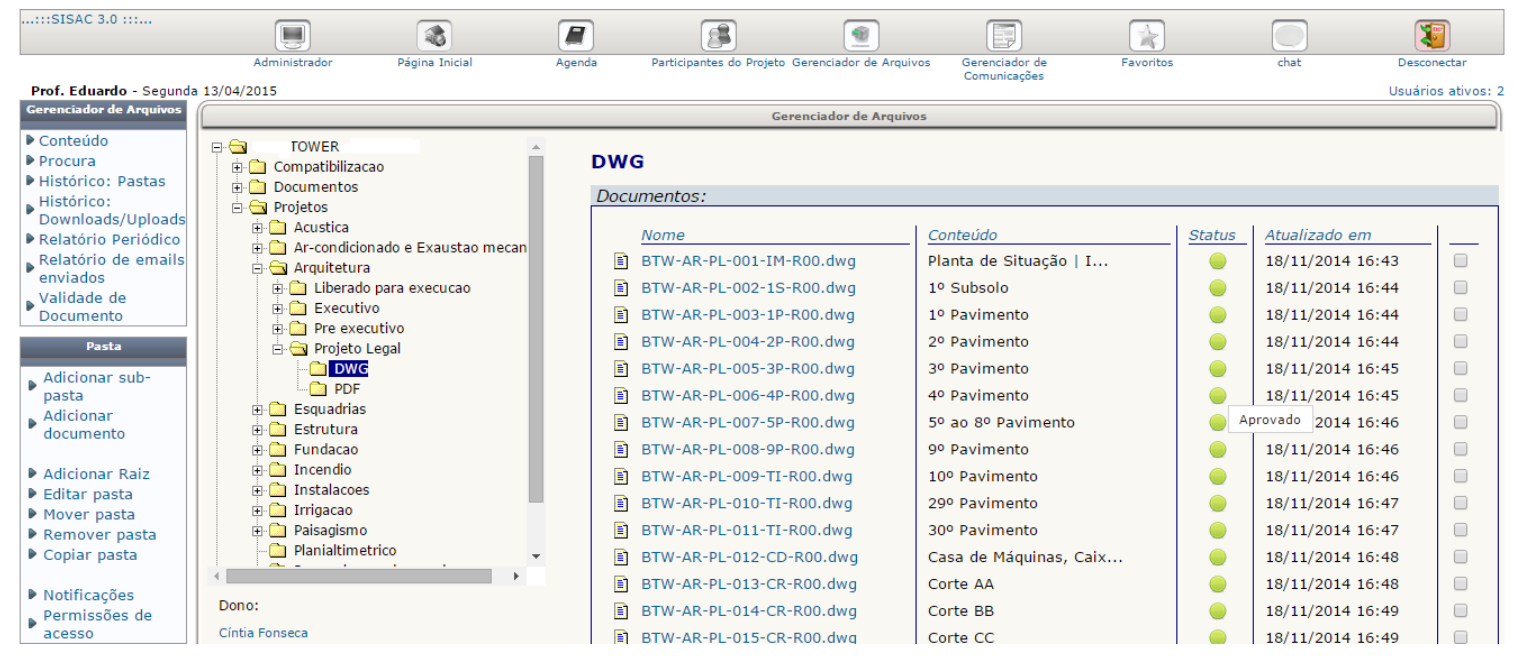


Para análise da utilização da extranet nas empresas e empreendimentos foram utilizadas as seguintes fontes de evidências, em todos os empreendimentos objeto de estudo:

(a) arquivos de projetos, em suas distintas especialidades e fases de execução;

(b) documentos associados aos projetos, incluindo memoriais de cálculo e especificações e contratos; e

(c) registros de comunicação entre os agentes, incluindo e-mails, atas de reuniões, registros de notificações, conversas em chats.

Teve-se acesso, portanto, a um conjunto privilegiado de dados, o que permitiu a análise detalhada das formas de interação entre os agentes, bem como dos conteúdos e formas de comunicação no âmbito de atividades técnicas, gerenciais e comerciais.

A esses dados documentais somaram-se entrevistas semiestruturadas, conduzidas com os cinco coordenadores de projetos e gestores da utilização das extranets nas empresas estudadas. Os questionários abarcaram os seguintes aspectos:

(a) abrangência de participação e forma de utilização dos ambientes;

(b) nível de interação entre participantes, tanto no nível das atividades de projeto, como em obra e entre as duas atividades;

(c) melhorias nos processos de projeto e integração projeto-obra;

(d) redução de custo e prazo de projetos e outras atividades; e

(e) dificuldades e resistências ao uso da tecnologia; propostas de melhoria do ambiente colaborativo.

Todas essas análises foram validadas mediante cruzamento das entrevistas com as fontes documentais: detalhamentos das disciplinas de projetos, registros de comunicação entre especialidades, atas de reunião e relatórios de compatibilização.

\section{Considerações sobre a utilização de extranet de projeto por longo tempo}

Em função da grande quantidade de dados, optouse por apresentar uma análise sintética e de conjunto dos empreendimentos estudados nas cinco empresas objeto do estudo de caso. Os resultados dizem respeito à motivação e benefícios da utilização do ambiente colaborativo na gestão do processo de projeto de edificações, ressaltando aspectos associados ao uso prolongado do ambiente que não puderam ser observados na literatura recente, e finalmente aspectos associados às dificuldades e limitações no uso da extranet.

\section{Aspectos gerais}

Por determinação dos coordenadores do sistema e em sintonia com o grupo de pesquisa desenvolvedor do ambiente virtual, desde o início dos trabalhos somente dados introduzidos no ambiente colaborativo seriam considerados válidos. Nessa direção, procurou-se evitar o uso de outros meios de comunicação projetual entre os participantes do projeto, como telefone, e-mail particular, fax, entre outros. Essa medida foi estrategicamente definida pelos coordenadores para evitar problemas de comunicação e de documentação ao longo do processo de projeto.

Com a centralização das informações, observou-se que a validação de documentos e informações no ambiente facilitou o trabalho da coordenação, porque evidenciou para a equipe de projeto os prazos para elaboração, verificação e aprovação dos documentos. Vale lembrar também as facilidades inerentes à colaboração simultânea, obtidas na distribuição de informações, indexação e extração de documentos, agendamento e planejamento de atividades, bem como o respeito dos projetistas ao fluxo estabelecido no processo de projeto.

Em uma análise comparativa dos empreendimentos que foram suportados pelo ambiente colaborativo e outros empreendimentos similares e anteriores das empresas, nos quais foram envolvidos os mesmos projetistas, foi constatada como evidência obtida das entrevistas a diminuição de prazos de desenvolvimento dos projetos em função das facilidades que o sistema proporciona para o controle de prazos. Entre esses instrumentos estão notificações, avisos automáticos de carga de arquivos de projeto $\mathrm{e}$ ferramentas de controle de prazos. Um controle mais efetivo por parte dos coordenadores de projeto parece também ter induzido uma atitude de maior comprometimento por parte dos projetistas.

De acordo com os relatos de um dos coordenadores, a centralização de dados em um único sistema com acesso rápido às informações projetuais foi uma das ferramentas-chave para o aumento da confiabilidade no fluxo de informações e redução dos tempos de espera por troca de informações, tornando o processo de projeto mais eficiente. Outro dos entrevistados relatou reduções da ordem de $10 \%$ de prazo projetual em relação a outros processos similares

154 Andery, P. R. P.; Arantes, E. M. 
de projeto que não fizeram uso do sistema colaborativo.

Nesse aspecto foi possível constatar em conversa com os participantes do processo de projeto que a centralização de documentos (arquivos dos projetos executivos com extensão $d w g$, doc, $x l s e$ $p d f$ ), com acesso rápido e fácil pela internet, aumentou a adesão ao sistema colaborativo.

Não obstante as facilidades da coordenação de projetos inerentes a essa centralização, a existência de um banco de dados centralizado e as ferramentas de gestão de documentos transformaram-se no principal motivo de adesão ao sistema, como já foi reportado na literatura. Nesse contexto e no que se refere ao uso do sistema, os coordenadores de projetos afirmaram que a simplicidade de operação dele foi um dos fatores que motivou a implementação e uso intensivo da ferramenta. O comentário é coerente com a afirmação de Nitithamyong e Skibniewski (2011), que indicaram que a simplicidade na implementação e operação dos ambientes colaborativos é um dos fatores que facilitam sua utilização.

No que se refere aos modelos de fluxo de informações, observa-se um modelo centralizado nos coordenadores: os diálogos foram idealizados de forma que as interações ocorressem entre usuários e coordenadores. $\mathrm{O}$ motivo principal dessa conduta é que os coordenadores dos projetos tinham status de "proprietários" da extranet, por pertencerem à incorporadora e/ou construtora contratante do Sisac. Além disso, o funcionamento do ambiente colaborativo foi estruturado de forma hierárquica e de acordo com os interesses das empresas pesquisadas, de forma que a coordenação era responsável pela modelagem das informações, ou seja, a modelagem do fluxo de informações foi feita pelos coordenadores dos projetos dos empreendimentos, que assumiram, via de regra, um papel de centralização das informações.

Vale destacar o estabelecimento de uma nomenclatura padronizada para todos os documentos dos empreendimentos, uma questão elementar na gestão do desenvolvimento dos projetos, mas inédita para as construtoras estudadas. Nessa direção, a visualização das normas para postagem de documentos encontravase sempre disponível para os usuários do sistema.

Conforme relato dos coordenadores, no começo das atividades muitos projetistas não acreditaram na padronização dos documentos devido a tentativas anteriores malsucedidas. Entretanto, conforme também mencionado por quatro coordenadores de projetos, a existência do ambiente colaborativo por si só induziu a indexação padronizada dos documentos.

O recurso de diferenciação de leitura e escrita de documentos e informações para os usuários foi considerado pelas equipes de trabalho essencial para o sucesso da gestão do processo de projeto dos empreendimentos. De acordo com os entrevistados, a possibilidade de definir direitos de leitura e/ou escrita de documentos para diferentes usuários disciplina o trabalho dos projetistas, bem como organiza as informações de projeto.

Um dos fatores incentivadores ao uso da extranet, segundo os coordenadores das empresas, foi a intensa comunicação entre coordenadores e projetistas por meio do sistema e, em menor escala, entre os projetistas de distintas especialidades. Essa comunicação foi mais ou menos intensa nas dezenas de empreendimentos considerados e variou significativamente em seu objeto, tratando desde questões burocráticas e contratuais até a utilização da extranet como ferramenta de colaboração para o desenvolvimento de soluções projetuais integradas, como foi o caso de alguns empreendimentos da empresa $\mathrm{E}$.

Esse aspecto parece estar associado, por um lado, a um maior envolvimento dos agentes e, por outro, ao fato de que nos empreendimentos nos quais houve efetiva colaboração foram previamente definidos planos de comunicação e colaboração entre os agentes, que é condição para a eficácia da colaboração, como aponta a literatura recente (MANZIONE et al., 2011; MELONI, 2008).

A central de documentos e as informações da página inicial serviram não somente para a indexação, distribuição e discussões para a compatibilização dos projetos, mas também para o estabelecimento de prazos, aprovações e pendências projetuais. De acordo com entrevistas com os coordenadores do sistema, o maior envolvimento com as fases do projeto aumentou a eficiência dele, uma vez que as pendências projetuais eram visualizadas e/ou acompanhadas por todos os usuários do sistema a qualquer momento.

Segundo os coordenadores, de um lado, o uso do ambiente colaborativo diminui o número de reuniões de projeto e o recebimento constante de chamadas telefônicas para solucionar problemas. Isso se explica pelo amplo acesso e distribuição de informações de projeto no interior do sistema. Por outro lado, todos os projetos analisados foram desenvolvidos com softwares gráficos com modelagem 2D, com muitas revisões nos projetos detalhados, sobretudo em relação aos sistemas prediais. 
Uma melhor colaboração usando extranets dependerá de um adequado balanço entre comunicação on-line e presencial (OTTER; EMMIT, 2007), bem como de um adequado entendimento sobre as formas de relacionamento entre agentes de equipes temporárias de projeto (EMMIT, 2011). Por outro lado, as extranets dificilmente substituirão totalmente reuniões entre os agentes, nas que decisões estratégicas são tomadas e são definidos os requisitos e valores assumidos no projeto, particularmente no caso de projetos complexos (EMMIT; GORSE, 2009).

Se, por um lado, a presente pesquisa confirma as afirmações dos autores, por outro, observou-se sistematicamente diminuição de reuniões para as empresas com mais de dez empreendimentos pesquisados. De acordo com os entrevistados, tal constatação foi atribuída ao uso prolongado do ambiente virtual, que tornou mais fácil o acesso confiável às informações e permitiu a troca de impressões via web, reduzindo a necessidade de contatos presenciais.

Para além dos mecanismos de comunicação, gerenciamento de documentos e controle de prazos projetuais, como os pesquisadores tiveram acesso ao conjunto de dados de todos os empreendimentos que utilizaram o sistema, foi possível verificar como se deu o fluxo de informações em versões de um mesmo projeto e na interface entre as disciplinas de projeto.

Contudo, a pesquisa evidenciou que as especialidades de Arquitetura e Estruturas são aquelas em que ocorre o maior número de consultas e/ou registros de uso das equipes de projeto. Isso mostra como essas duas áreas continuam sendo os "carros-chefes" dos projetos. A Figura 2 exemplifica a distribuição percentual desse fenômeno nos empreendimentos residenciais das empresas pesquisadas.

Via de regra, o uso da extranet se manteve ativo nos empreendimentos pesquisados por cerca de 3 anos, com colaboração simultânea durante o período de 1 ano referente ao desenvolvimento dos projetos básicos e executivos. Isso pôde ser verificado por meio de:

(a) comunicação entre os projetistas com o coordenador e projetistas entre si;

(b) acesso dos agentes aos documentos de projeto de outras disciplinas; e

(c) cronograma de desenvolvimento dos projetos e datas de carga e descarga de arquivos.

A Figura 3 ilustra a simultaneidade entre as especialidades de projeto em mais de $80 \%$ dos empreendimentos analisados. Contudo, o conjunto de dados não permitiu a criação de métricas específicas para avaliação da integração entre as disciplinas de projeto durante seu desenvolvimento. Verifica-se a simultaneidade do desenvolvimento das disciplinas de projetos e o acesso sistemático de umas aos documentos das demais. Nesse sentido, levanta-se a hipótese de que o desenvolvimento simultâneo dos projetos, como pôde ser verificado pelo controle de acessos, tenha gerado mecanismos de integração e efetiva colaboração, em maior ou menor escala, segundo os casos.

\section{Figura 2 - Porcentagem representativa dos acessos aos projetos pelas diferentes especialidades}

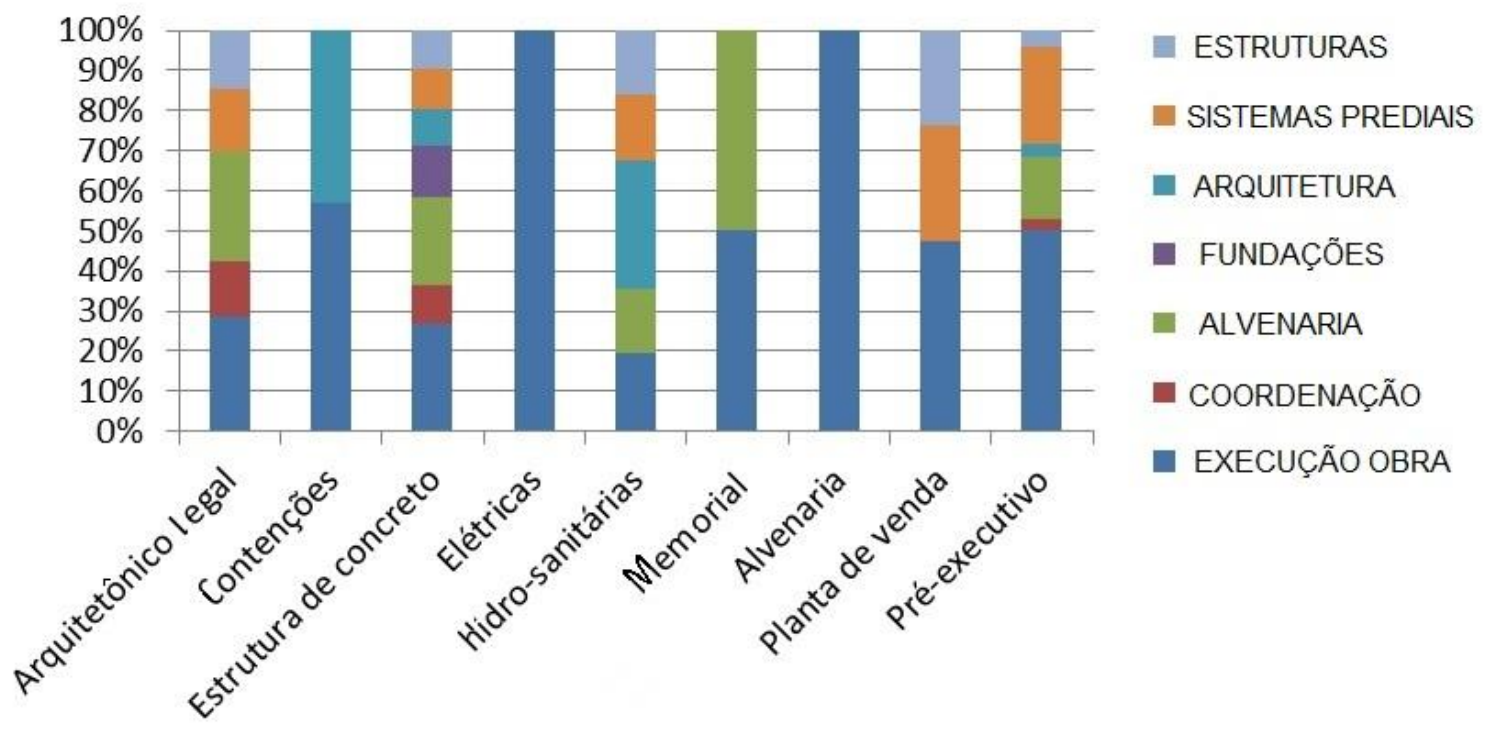

156 Andery, P. R. P.; Arantes, E. M. 
Figura 3 - Quadro característico do processo colaborativo dos empreendimentos

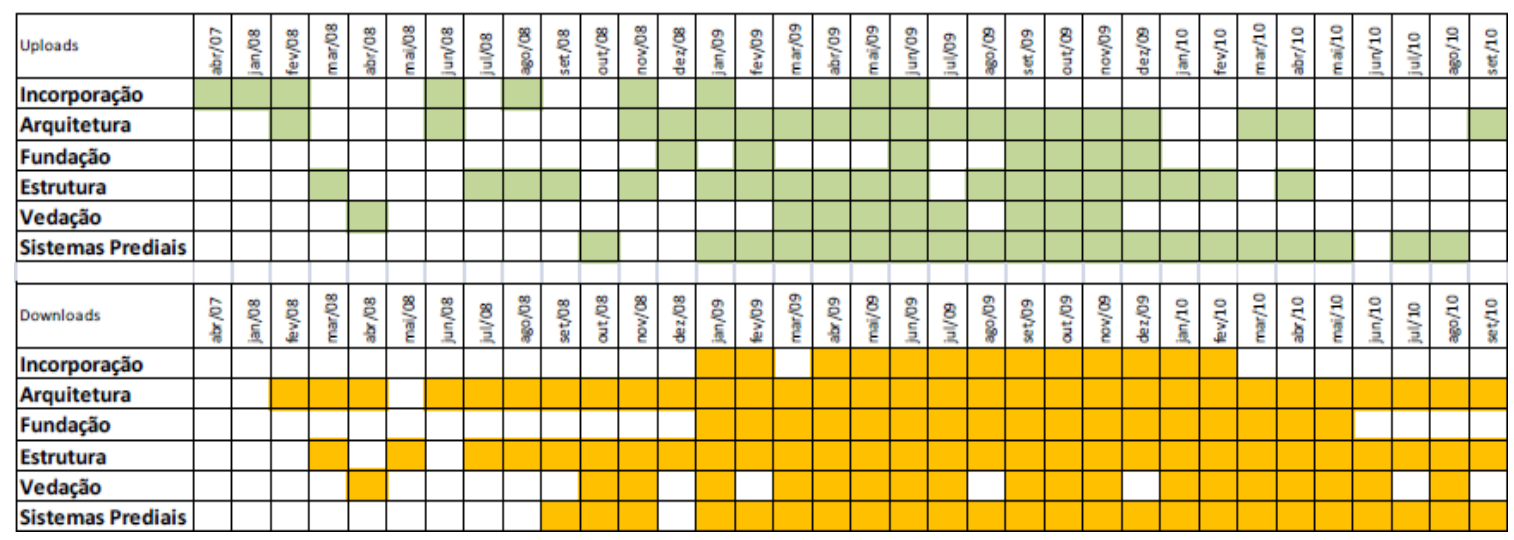

Sobre o planejamento e gestão de plano de trabalho estruturado para a solução de conflitos de caráter conceitual ou espacial em especialidades de projeto, vale mencionar a modelagem que foi estruturada nos ambientes das obras comerciais das empresas B e E. O plano de ação foi estruturado em forma de tópicos com tecnologia de fóruns online interligados às caixas de e-mails dos interessados.

O processo se desenvolvia da seguinte forma: a discussão iniciava-se por qualquer agente de projeto devidamente autorizado para realizá-la. Conforme modelo estruturado pelo coordenador de projeto, a comunicação inicial era remetida automaticamente para todos os e-mails cadastrados na discussão. Na modelagem do sistema, nem todos os agentes que recebiam as mensagens podiam intervir no processo. Os agentes que podiam $o$ faziam diretamente na mensagem recebida, por meio de link no final do texto, de forma que todas as informações eram centralizadas no sistema e novamente remetidas aos mesmos participantes. Além disso, as dez últimas comunicações enviadas ao sistema eram automaticamente postadas na página inicial do sistema, a quem de direito o possuísse, com o objetivo de deixar explícito o fluxo de informações em processo, conforme é mostrado na Figura 4, na qual nomes dos projetistas e coordenadores de projetos foram omitidos.

Dessa forma, buscou-se eliminar o problema do isolamento da informação nas caixas de e-mail dos agentes, uma vez que toda informação era centralizada no sistema de forma organizada e estruturada. Isso representou uma vantagem para os coordenadores e subcoordenadores de áreas, que podiam acompanhar todo o fluxo de informações e intervir nos processo quando necessário.

\section{Considerações sobre o uso prolongado do ambiente colaborativo}

O uso contínuo do ambiente colaborativo mostrou alguns avanços de modelagem da extranet de projeto que permitiram não somente o aperfeiçoamento da colaboração entre os agentes, mas também a ampliação de novas formas de interação.

Nesse contexto, destacam-se:

(a) uso mais amplo da extranet, para além das atividades de gestão do processo de projeto; e

(b) planejamento e gestão de plano de trabalho estruturado para a solução de conflitos de caráter conceitual ou espacial em especialidades de projeto, servindo o sistema como ferramenta de desenvolvimento de soluções efetivamente integradas e colaborativas.

Com exceção da empresa $\mathrm{D}$, que utilizou a colaboração exclusivamente para o desenvolvimento dos projetos executivos, todas as demais extranets serviram não somente ao propósito inicial de gestão do processo de projeto, mas também foram utilizadas para o gerenciamento das atividades nos canteiros de obras, particularmente na gestão de documentos, como diários de obras, registro fotográfico da execução das atividades construtivas ou acompanhamento dos cronogramas físicos e financeiros. Em especial, a empresa $\mathrm{C}$ ampliou o uso do sistema para muitos outros setores correlacionados ao processo de projeto e obra, como contábil, jurídico e de comercialização, conforme é mostrado na Figura 5. 
Figura 4 - Exemplo das 10 informações (mais recentes) remetidas a pagina inicial do sistema

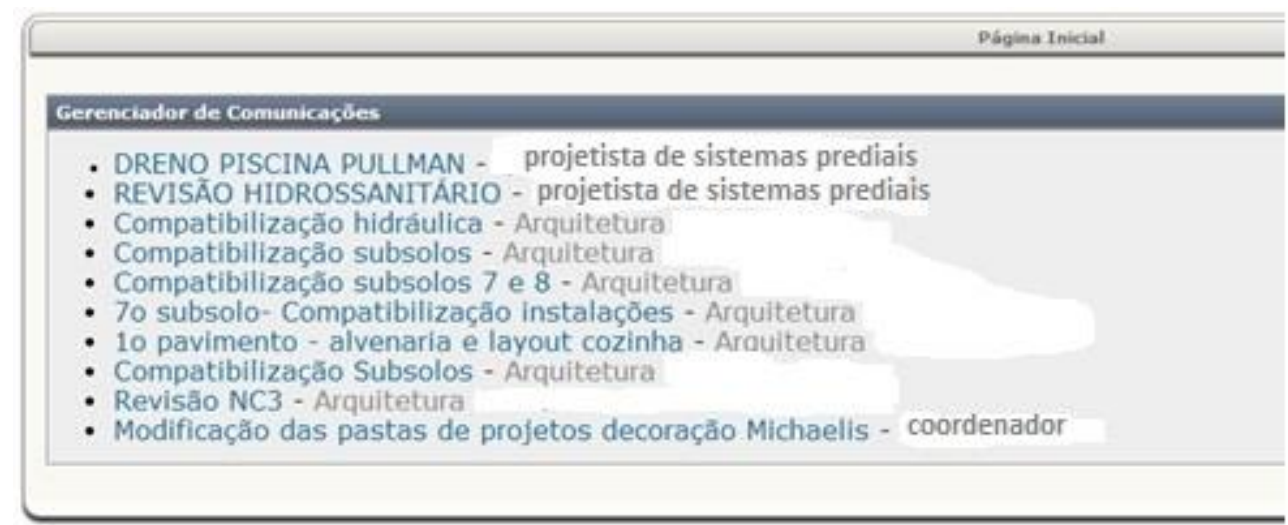

Figura 5 - Exemplo de uso amplo do sistema - obra da empresa C

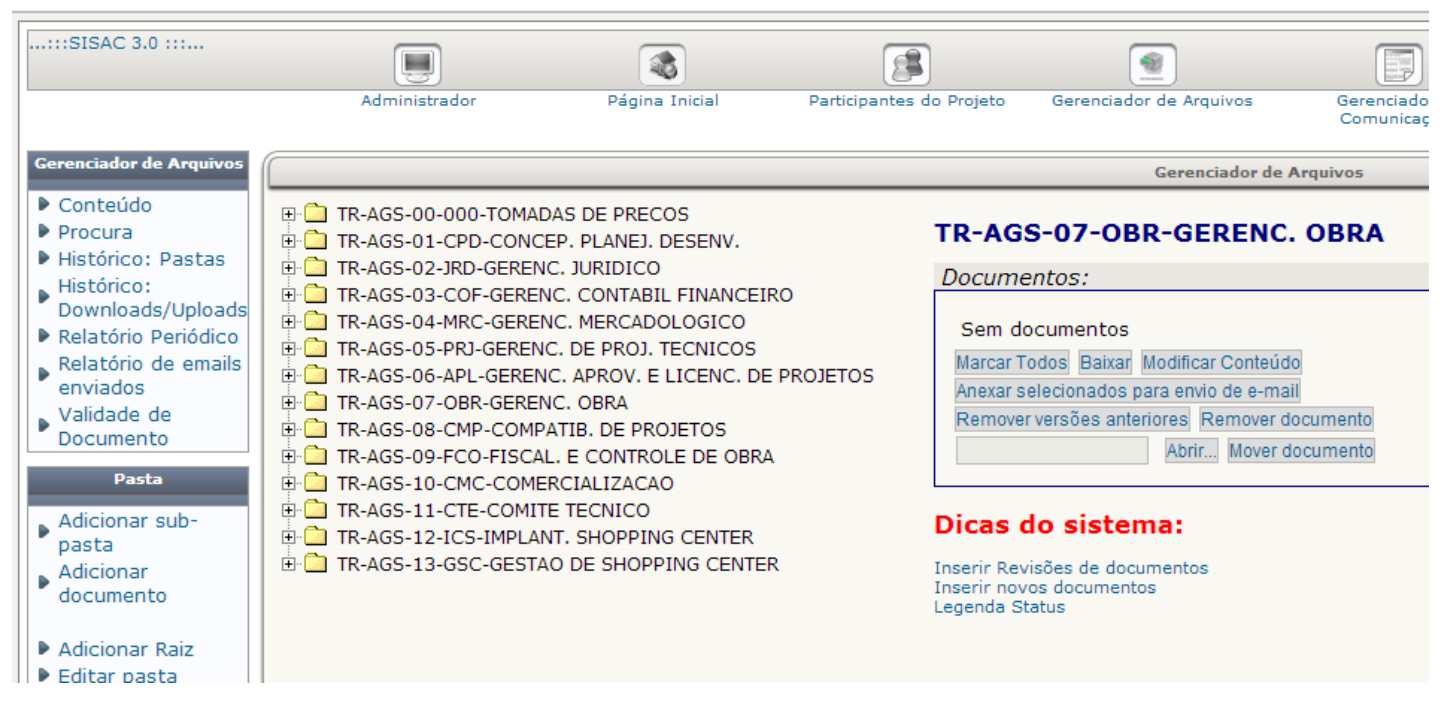

Para atender a essas demandas da empresa foi criado um grupo no sistema denominado "SubCoordenação", de modo que os responsáveis pelas áreas diversas pudessem administrar suas próprias áreas. Tal recurso possibilitou que coordenadores de área pudessem inserir novos usuários e novos grupos de usuários de forma independente e autônoma.

Diretórios específicos para subcoordenadores de áreas foram criados para que tivessem acesso total a documentos e pastas, mas de maneira restrita a cada área específica. Vale ressaltar que a coordenação de projeto continuou tendo acesso irrestrito e controle total de todas as informações processadas no sistema. Mais ainda, a inserção de agentes não diretamente envolvidos com o processo de projeto facilitou a comunicação entre a equipe de projeto e outras equipes envolvidas com a gestão do empreendimento.

$\mathrm{Na}$ maior parte dos acessos à extranet as análises mostram que cada subcoordenador de área e sua respectiva equipe, num primeiro momento, fizeram uso e gestão de comunicação e de seus diretórios e documentos de forma isolada.

Entretanto, ao longo do desenvolvimento dos projetos foram observados cruzamentos de informações com outras áreas, com fluxos interdependentes nos momentos em que o projeto requereu intervenções diversas. Entre as interligações mais relevantes entre projeto $\mathrm{e}$ demais áreas, podem-se destacar os agentes da área de planejamento e desenvolvimento, jurídico, contábil financeiro e comercialização, fato não verificado quando do uso inicial da ferramenta.

No que se refere às contribuições do ambiente à melhoria da construtibilidade dos empreendimentos pesquisados foram verificadas iniciativas da coordenação com o intuito de promover a integração entre os projetistas e dos projetistas com engenheiros executores. Isso se deu na medida em que o ambiente colaborativo foi instrumento de marcação de constantes reuniões para discussão dos projetos, com foco na eliminação de interferências projetuais, assim 
como na adequação dos projetos às especificações e execução de materiais na obra, no sentido de obter melhor racionalização e melhor execução dos serviços.

A Figura 6 mostra o agendamento de reunião de projeto envolvendo diversos agentes de projeto e construtora. Como foi feito na Figura 4, os nomes dos agentes e/ou empresas foram retirados da imagem.

Outro exemplo da colaboração mais ampliada foi constatado na empresa $\mathrm{B}$, gestora de shopping centers, a partir da demanda de abrir outro ambiente que possibilitasse a gestão dos projetos individuais no interior das lojas. Assim, posteriormente à gestão do processo de projeto dos shoppings, os lojistas e seus fornecedores de projeto foram cadastrados numa área específica do ambiente colaborativo com o intuito de que cada cliente lojista pudesse não somente desenvolver seus próprios projetos executivos, mas também aprová-los junto à administradora do shopping. Vale ressaltar que essa perspectiva de uso posterior ao processo de projeto e obra não foi inicialmente planejada, ou seja, surgiu bem depois da contratação do ambiente virtual, em virtude das possibilidades de uso no processo pós-obra. Isso mostra que os investimentos em extranets de projeto são capazes de beneficiar seus contratantes de diversas formas, à medida que se aperfeiçoam processos internos de produção das empresas, assim como se melhora a relação técnica-comercial dos contratantes com seus clientes.

Ainda sobre as possibilidades de uso ampliado do Sisac, a extranet tem funcionado como intranet visando à centralização das informações dos sistemas de gestão da qualidade das empresas A e B, como ilustrado na Figura 7. A pesquisa mostra que o ambiente da empresa $B$ reúne mais de seiscentos funcionários cadastrados no SGQ da empresa para acesso de documentos, formulários, manuais, procedimentos, normas e avisos internos.

\section{Problemas e dificuldades no uso da extranet}

No que diz respeito aos pontos críticos ou negativos que trouxeram dificuldades na colaboração dos processos analisados, destacam-se três questões:

(a) a primeira questão é caracterizada como sendo uma forma específica de "resistência", oriunda do uso prolongado da ferramenta;

(b) a segunda tem relação com a descontinuidade da comunicação nos processos; e

(c) a terceira tem associação com a falta de envolvimento dos promotores dos empreendimentos.

Figura 6 - Marcação de reunião entre agentes visando a melhorias dos projetos

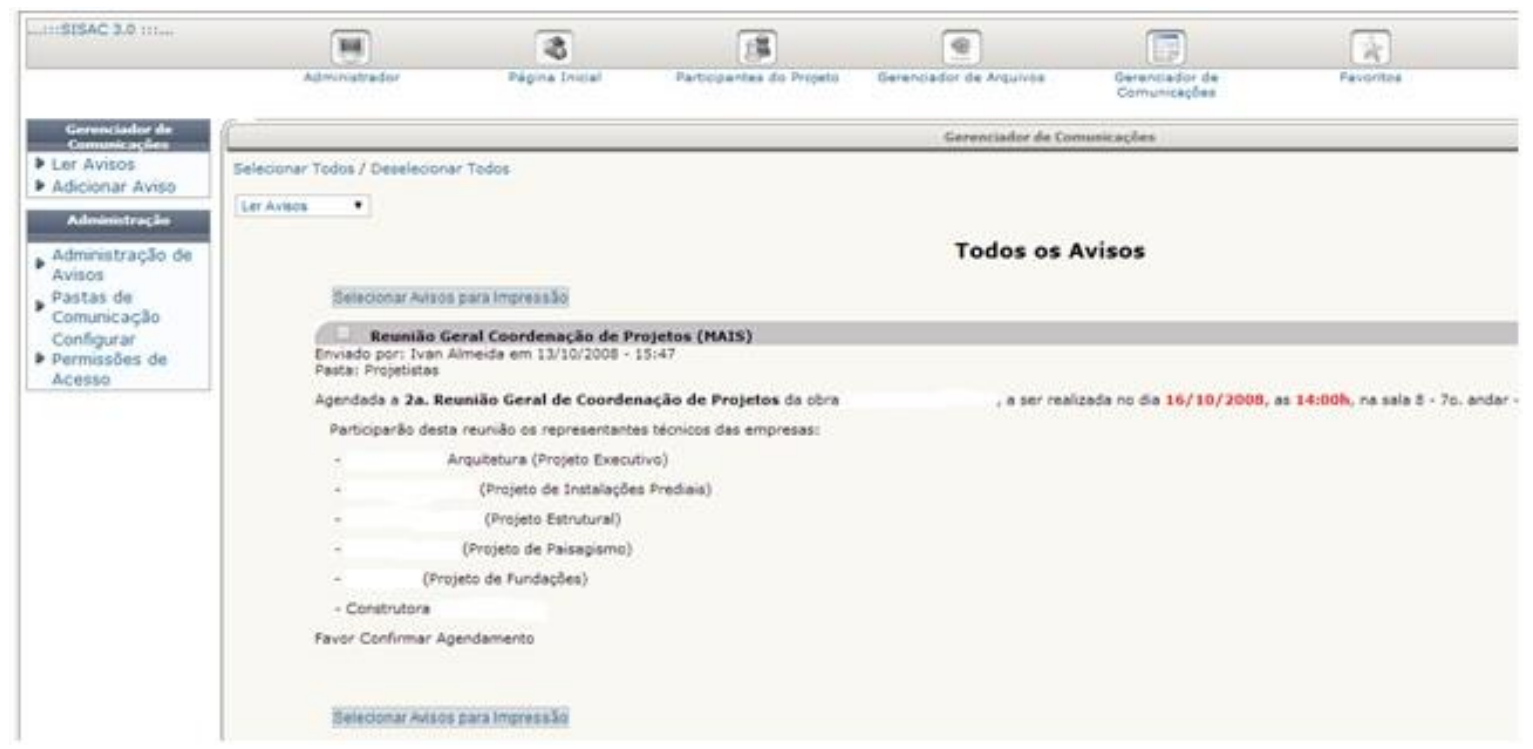


Figura 7 - Exemplo de ambiente do SGQ da empresa B

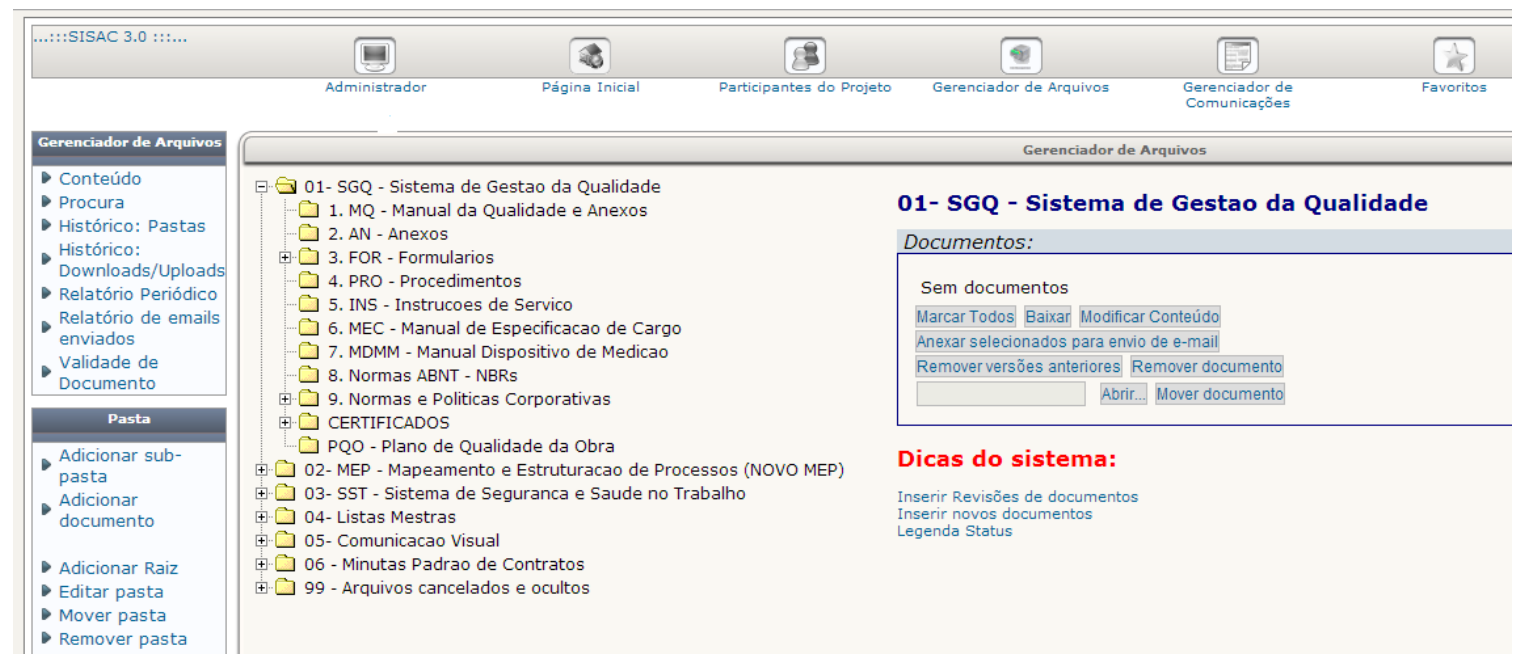

Com relação à primeira questão, observaram-se alguns aspectos contraditórios: por um lado, o uso prolongado da extranet permitiu melhorias na gestão de documentos, controle de prazos de projeto e a utilização da extranet como fórum de solução de problemas multidisciplinares e de interface entre projetos. Por outro, constatou-se um fenômeno que foi denominado "resistência por acomodação". Esse termo se explica na medida em que não se observaram mudanças de caráter gerencial, devido à não implantação de novos recursos e/ou possibilidades que a extranet oferece. Ou seja, a utilização da extranet, para além das vantagens advindas da familiaridade com a ferramenta, não implicou mudanças substanciais na gestão do processo de projeto, e, ao longo dos empreendimentos, a forma de utilização foi basicamente a mesma.

Contudo, verificou-se que essa resistência variou de empresa para empresa: na empresa A a resistência por acomodação é evidente, uma vez que essa empresa buscou na extranet uma simples ferramenta de centralização da informação. $\mathrm{Na}$ empresa B o fenômeno é claro, mas com alguns avanços isolados na gestão da comunicação. $\mathrm{Na}$ empresa D recursos de comunicação fornecidos pelo sistema, como o gerenciamento de comunicações e o chat, nunca foram usados, não obstante o uso contínuo da extranet em vários empreendimentos sucessivos da empresa. $\mathrm{Na}$ empresa $\mathrm{E}$, em empreendimentos específicos, a extranet permitiu a colaboração entre os projetistas no desenvolvimento integrado de projetos.

Dessa maneira, implementa-se uma nova forma de trabalho colaborativo computacional, mas não se observa a preocupação dos agentes em experimentar novas formas de trabalho, de maneira a tornar o processo de projeto ainda mais produtivo ou mais eficiente.

Outro aspecto observado está diretamente associado à postura dos agentes, que, ao longo do processo de projeto, deixaram de utilizar funcionalidades do ambiente colaborativo, como é o caso dos recursos de gestão da comunicação.

A título de exemplo, ao longo do processo de projeto, discussões são promovidas e soluções ocorrem em função disso, com destaque para interferências entre as especialidades e/ou dúvidas sobre os impactos de uma proposição de projeto entre os agentes. Entretanto, em determinados casos, o uso prolongado do sistema mostrou descontinuidade nas comunicações, na medida em que os diálogos na extranet não registraram as soluções ou decisões da equipe, ou até mesmo foram abandonados. Nesse contexto, as fontes de pesquisa mostram "desvios de conduta" dos usuários, que foram observados por lacunas existentes nos bancos de dados dos empreendimentos estudados, comprovados por meio das entrevistas com os coordenadores de projeto. De acordo com esses coordenadores, em alguns casos houve envio de mensagens por e-mail diretamente aos parceiros, de forma que o fluxo de comunicação não se concretizou pela extranet.

Outro aspecto que merece destaque é o fato de os diretores das empresas (ou agentes hierarquicamente superiores e responsáveis pelos empreendimentos) não se envolveram com os ambientes colaborativos. Uma das evidências do pequeno envolvimento dos empreendedores está no fato de que, quase sempre, a extranet foi vista não como um recurso, mas como um custo, além do fato de que com frequência houve a pressão para diminuir o valor financeiro associado à 
utilização da tecnologia da informação. Em duas das cinco empresas estudadas em nenhum momento houve por parte dos empreendedores interesse em colaborar para o aprimoramento das funcionalidades do sistema.

Diversos autores (RUIKAR; ANUMBA; CARILLO, 2005; LIU; KAGIOGLOU, 2008; NITITHAMYONG; KIBNIEWSKI, 2011) realizaram estudos comparativos indicando funcionalidades das extranets orientadas à gestão de projetos, tanto no contexto do empreendimento quanto na fase de desenvolvimento do produto. Em seu conjunto, os autores destacam as funções:

(a) módulos administrativos, que permitem a configuração da estrutura do sistema, definem os tipos de acesso e parâmetros de segurança, permitem configurar o uso para múltiplos agentes e projetos, etc.;

(b) funções de gerenciamento de documentos, envolvendo a carga e descarga de documentos, a emissão de notificações, a rastreabilidade dos documentos, o registro de fluxo de trabalho, etc.;

(c) funções de gerenciamento do fluxo de informações e tarefas, integrando tarefas e disciplinas, aplicando ferramentas de gerenciamento de projetos (custo, prazo, escopo), permitindo a integração de fluxo de trabalho, etc.; e

(d) ferramentas de comunicação.

O uso da extranet nas cinco empresas de noventa e seis empreendimentos estudados aponta para as mesmas funções sendo empregadas, com ênfase para a gestão de documentos de projeto e controle de prazos de execução dos projetos. Em menor escala, as extranets foram utilizadas para definir um fluxo de trabalho e como ferramenta de colaboração no desenvolvimento integrado de projetos, esse último aspecto observado pontualmente.

Observa-se, portanto, um "padrão de comportamento" no uso da extranet bastante semelhante ao reportado pela literatura recente. De fato, o uso da extranet de maneira contínua e prolongada não significou, com exceção de alguns casos, o uso de novas funcionalidades ou um avanço nas formas de colaboração desdobradas no desenvolvimento integrado e simultâneo dos projetos.

Nos casos em que as extranets funcionaram como ferramentas de efetiva colaboração, houve atuação mais marcante dos coordenadores de projeto e uma atitude proativa por parte dos projetistas, sendo o ambiente mais uma ferramenta de comunicação para a colaboração do que um indutor do uso de princípios de engenharia simultânea. Nesse sentido, o comportamento dos agentes com relação ao uso da extranet confirma observações da literatura dos últimos anos. Nessa direção, a Figura 8 mostra o perfil característico de colaboração de empreendimentos da empresa A no período de agosto de 2007 a agosto de 2010, com diferentes intensidades de interação das especialidades de projetos, em momentos específicos e em virtude do volume de trabalho demandado. Os dois principais picos do gráfico referem-se às revisões entre as especialidades de Arquitetura e Estrutura e alterações nos projetos de Sistemas Prediais.

Figura 8 - Caracterização da colaboração em empreendimentos da empresa A

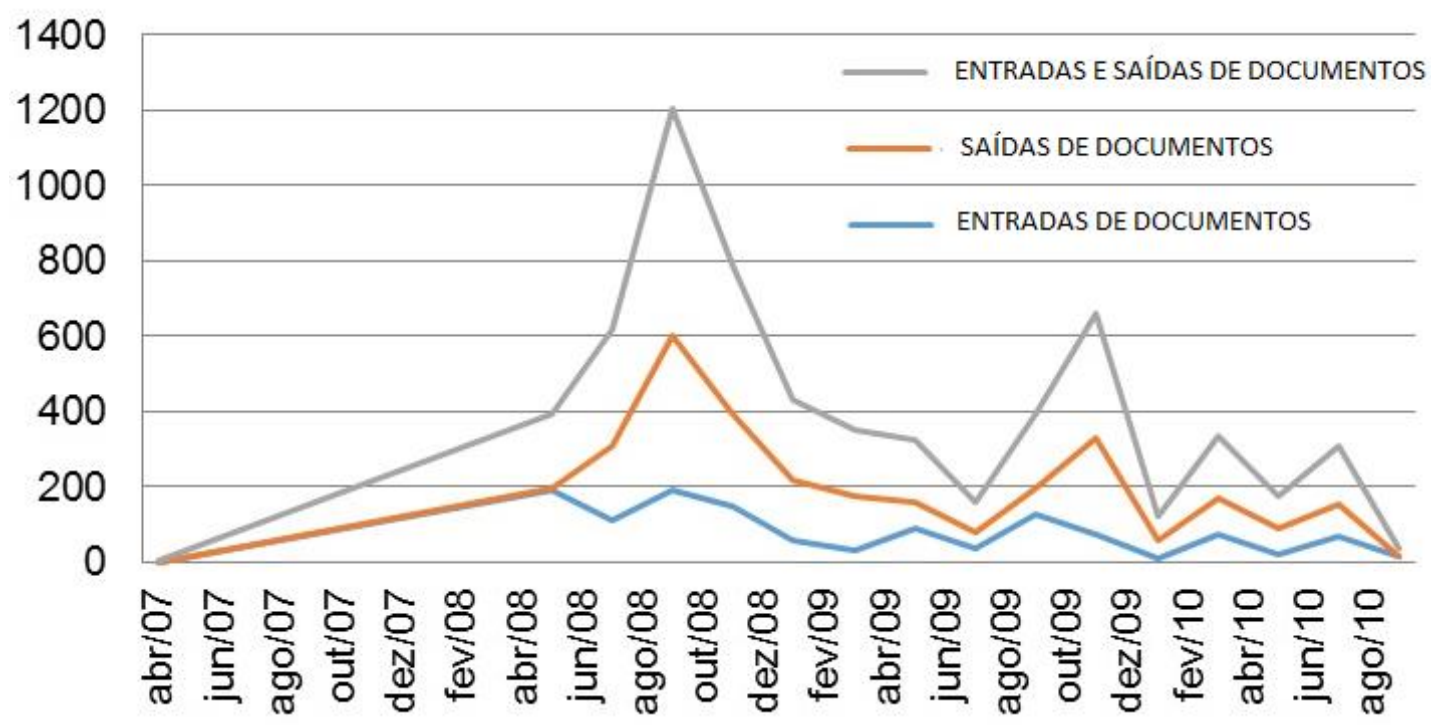


Com referência aos diversos empreendimentos que foram estudos nesta ampla pesquisa, pode-se concluir que formas mais inovadoras de colaboração vão decorrer mais de uma mudança de cultura e compromisso dos agentes envolvidos do que de maior familiaridade ou da consolidação de rotinas de uso das extranets (BJORK, 2002; MANZIONE; MELHADO, 2004; DE BLOIS; HERAZO CUETO, 2011)

Nesse sentido, Emmit e Gorse (2009) e Manzione et al. (2011) comentam que, não obstante as existência de ferramentas computacionais de colaboração, como é o caso das extranets, torna-se fundamental para melhor desempenho da colaboração definir e desenvolver competências individuais e formas interpessoais de interação.

Por outro lado, com poucas exceções, os mecanismos de comunicação entre projetistas e desenvolvimento integrado dos projetos foram obstaculizados pela ausência de um plano de comunicação e integração de atividades de projeto, que, como se observa na literatura, é condição essencial para que uma colaboração mais intensa se efetive por meio das extranets (MANZIONE et al., 2011; MELONI, 2008). Nesse sentido, a tecnologia da informação não se encerra nela mesma, ou seja, faz parte de um modelo de gestão capaz de instigar novas formas de agir e coordenar os agentes da construção. A isso se soma o fato de que na quase totalidade dos casos o uso das extranets não foi uma decisão de estratégia das empresas, nem contou com o apoio dos tomadores de decisão dos empreendimentos, e quase sempre foi encarado como ferramenta para o gerenciamento e controle de documentos da etapa de projeto.

Os resultados deste trabalho contribuem no sentido de comprovar que, com a passagem do tempo, o uso contínuo do ambiente colaborativo, não obstante certa resistência de alguns agentes em empreendimentos específicos, consolida formas de gestão de documentos e comunicação, ainda que sem inovações e desenvolvimento de formas mais aprimoradas de trabalho, ou mesmo a utilização de outras funcionalidades disponíveis que pudssam facilitar a colaboração.

\section{Conclusões}

A presente investigação buscou analisar e problematizar as mudanças que ocorreram num ambiente virtual colaborativo ao longo de oito anos de trabalho de pesquisa em que se desenvolveram noventa e seis empreendimentos de construção civil. Se, por um lado, a análise de muitos empreendimentos evidencia benefícios e dificuldades semelhantes aos que se verificam na literatura sobre extranets de projeto, por outro lado, o uso prolongado da tecnologia permitiu identificar novas formas de atuação e de resistência dos agentes de construção em relação a essa tecnologia.

Em relação às formas de atuação, as análises evidenciam que a contratação da extranet de projeto tem motivação na gestão do processo de projeto, em grande parte por iniciativa isolada dos coordenadores de projeto, que buscam a adesão dessa colaboração nas e entre as empresas. De modo geral, a extranet nasce com a preocupação pela gestão do processo de projeto, com efetivas contribuições para a qualidade dos projetos pela interação sistemática entre projetistas, e se propaga para promotores e construtores com benefícios significativos para todos os agentes.

Entretanto, os ganhos nos contextos da construção civil (promoção, projeto e construção) são mais efetivos no interior de cada contexto propriamente dito do que entre eles, uma vez que os ambientes virtuais não são planejados antecipadamente com previsão de ampla colaboração para entre todos os agentes envolvidos. Assim, efetiva-se a colaboração entre agentes de projeto, mas falta uma visão estratégica e liderança da alta direção das empresas, que, ao longo do tempo, impedem que melhorias contínuas sejam implementadas no uso das extranets.

Nesse contexto e no que se refere às dificuldades devido ao uso prolongado da extranet, o trabalho mostra formas de resistência mais complexas, pelas dificuldades de os gestores dos empreendimentos de criar novas formas de trabalho ou de tornar os processos mais produtivos e/ou mais eficientes. Em relação isso, o fenômeno de "resistência por acomodação" ao longo do uso prolongado dos ambientes colaborativos é presente em todos os casos estudados.

Destacaram-se também a falta de planos de comunicação e as descontinuidades das comunicações quando planejadas. Se, por um lado, planos de comunicação serviram para resolver conflitos de ordem técnica e solucionar problemas de compatibilização dos projetos, por outro, os planos se destituíram gradativamente ao longo do processo de projeto, cujo principal motivo foi o uso de formas convencionais de comunicação como e-mail e telefone.

Vale destacar que as novas metodologias BIM tornaram obsoletas as funcionalidades das extranets no que tange ao controle de revisões de desenhos das especialidades devido às novas formas de modelagem tridimensional de forma integrada e/ou simultânea. Apesar dessa obsolescência, o estudo mostrou o potencial das 
extranets no gerenciamento de informações através de diferentes formas de comunicação entre os agentes da construção, manipulação e controle de documentos normativos, contratuais, administrativos, jurídicos e/ou gerenciais, e a possibilidade de armazenamento de modelos e/ou documentos oriundos das diversas etapas de modelagens BIM, incluindo detalhamentos, imagens, quantitativos, cronogramas e custos dos empreendimentos.

Em conclusão, a luta por melhor colaboração entre agentes da construção por meio das extranets não deve existir para substituí-las ou eliminá-las, mas para transformá-las, unindo-as ao conjunto de tecnologias da informação de colaboração simultânea em salas de reunião com telas interativas, ou em ambientes de realidade virtual imersiva que contribuam para a construção de empreendimentos de melhor qualidade, baixo custo e sustentáveis.

\section{Referências}

AMERICAN INSTITUTE OF ARCHITECTS. Integrated Project Delivery: a guide. Disponível em:

<http://www.aia.org/contractdocs/AIAS077630>. Acesso em: 10 ago. 2015.

ARANTES, E. M. Gestão do Processo de Projeto em Edifício Residenciais pelo Ambiente

Colaborativo SISAC. In: ENCONTRO

NACIONAL DE TECNOLOGIA DO

AMBIENTE CONSTRUÍDO, 12., Fortaleza, 2008. Anais... Fortaleza: ENTAC, 2008.

BJORK, B. The Impacts of Eletronic Document Management on Construction Information Management. In: CIB W078 SYMPOSIUM ON INFORMATION TECHNOLOGY FOR CONSTRUCTION, Rotterdam, 2002.

Proceedings..., Rotterdam: CIB, 2002.

DE BLOIS, M.; HERAZO-CUETO, B. Relationships Between Construction Clients and Participants of the Building Industry: structures and mechanisms of coordination and communication. Architectural Engineering and Design Mangament, v. 7, n. 11, p. 3-22, 2011.

EMMIT, S. Lean Design Management.

Architectural Engineering and Design Management, v. 7, n. 11, p. 67-69, 2011.

EMMIT, S.; GORSE, C. Informal Interaction on Construction Progress Meetings. Construction Management and Economics, v. 27, n. 10, p. 983-993, 2009.
LIU, N.; KAGLIOGLOU, M. An Investigation and Identification of Functions and Features or Project Extranets in Construction. In: CIB INTERNATIONAL POS GRATUDE RESEARCH CONFERENCE, 8., Praga, 2008. Proceedings... Praga: CIB, 2008.

MANZIONE, L.; MELHADO, S. Extranets de Projeto: limitações e necessidades de avanço. In: WORKSHOP BRASILEIRO DE GESTÃO DO PROCESSO DE PROJETO, Rio de Janeiro, 2004. Anais.... Rio de Janeiro: PROARQ UFRJ, 2004.

MANZIONE, L. et al. Challenges For Implementation of a New Model of a Collaborative Design Management: analyzing the impact of human factor. In: CIB W96 CONFERENCE, Viena, 2011. Proceedings... Viena: CIB, 2011.

MELONI, R. Project Management and Comunication in the Collaborative Building Design Process. In: CIB JOINT CONFERENCE: PERFORMANCE AND KNOWLEDGE MANAGEMENT, Rotterdam, 2008. Proceedings... Rotterdam: CIB, 2008.

NITITHAMYONG, P.; SKIBNIEWSKI, M. Success Factors For the Implementation of Web Based Construction Project Management Systems. Construction Innovation, v. 11, n.1, p. 13-42, 2011.

OTTER, A.; EMMIT, S. Exploring Effectiveness of Team Communication: balancing synchronous and asynchronous communications in design teams. Engineering, Construction and Architectural Management, v. 14, n. 5, p. 408419, 2007.

RUIKAR, K.; ANUMBA, C.; CARILLO, P. End User Perspectives on Use of Project Extranets in construction organizations. Engineering, Construction and Architectural Management, v. 12, n. 3, p. 225-235, 2005.

SCHEER, S. et al. The Necessary Background For Implementing and Managing Building Design Processes Using Web Environments. IT CON, v. 12, p. 221-230, 2007.

TRIBELSKY, G.; SACKS, R. Measuring Information Flow in Detailed Design of Construction Projects. Research in Engineering Design, v. 21, n. 3, p. 189-206, 2010.

WILKINSON, P. Features and Functionality of Construction Collaboration Technology. In: WILKINSON, P. Construction Collaboration Technologies. New York: Taylor \& Francis, 2005.

YIN, R. K. Estudo de Caso: planejamento e métodos. 3. ed. Porto Alegre: Bookman, 2005. 
Paulo Roberto Pereira Andery

Departamento de Engenharia de Materiais e Construcão Civil, Escola de Engenharia | Universidade Federal de Minas Gerais |

Av. Presidente Antônio Carlos, 6627, Bloco I, Sala 3314, São José | Belo Horizonte - MG - Brasil | CEP 31275-013 | Tel.: (31) 3409-1856

E-mail: paulo@demc.ufmg.br

\section{Eduardo Marques Arantes}

Departamento de Engenharia de Materiais e Construção Civil, Escola de Engenharia | Universidade Federal de Minas Gerais | Rua Espírito Santo, 35, Centro | Belo Horizonte - MG - Brasil | CEP 30160-030 | Tel.: (31) 3238-1854 | E-mail: arantes@ufmg.br

\section{Revista Ambiente Construído}

Associação Nacional de Tecnologia do Ambiente Construído

Av. Osvaldo Aranha, $99-3^{\circ}$ andar, Centro

Porto Alegre - RS - Brasil

CEP $90035-190$

Telefone: +55 (51) 3308-4084

Fax: +55 (51) 3308-4054

www.seer.ufrgs.br/ambienteconstruido

E-mail: ambienteconstruido@ufrgs.br

164 Andery, P. R. P.; Arantes, E. M. 